\section{In vitro activity of tigecycline against patient isolates collected during phase 3 clinical trials for hospital acquired pneumonia}

\author{
Peter J. Petersen, Margareta Tuckman, \\ C. Hal Jones \\ Infectious Diseases, Biosynthetic \\ Chemistry, Wyeth Research, Pearl River, \\ NY, USA
}

\section{Abstract}

The in vitro activity of tigecycline was evaluated against 819 baseline pathogens isolated from 383 patients enrolled in the phase 3 clinical trial investigating the efficacy of tigecycline in hospital acquired pneumonia (HAP). The trials were global, enrolling patients in 27 countries. Tigecycline was active against the most prevalent pathogens in HAP, including gram-positive and gram-negative strains (90\% of MICs $\leq 2 \mu \mathrm{g} / \mathrm{mL}$ for the entire collection). The spectrum of activity of tigecycline included important pathogens such as Staphylococcus aureus (including methicillin-resistant S. aureus), Enterococcus faecalis, Streptococcus pneumoniae, Acinetobacter baumannii/calcoaceticus complex, Escherichia coli, Klebsiella pneumonia, and Enterobacter cloacae. As reported previously, a few genera, such as Pseudomonas aeruginosa and the Proteeae, were generally less susceptible to tigecycline by comparison to other gram-negative pathogens. The excellent in vitro, expanded, broad-spectrum activity of tigecycline in the clinical isolates confirmed the potential utility of tigecycline for pathogens associated with with hospital acquired pneumonia infections.

\section{Introduction}

The glycylcycline class of antibiotics was developed by Wyeth in response to the threat of emerging antibiotic resistance throughout the world. ${ }^{1}$ Tigecycline, the first in the class glycylcycline, received market approvals for treatment of complicated skin and skin structure infections (cSSSI) and complicated intraabdominal infections (cIAI) in 2005 and community acquired bacterial pneumonia (CABP) in 2008 (see Tygacil Label at http://www. accessdata.fda.gov/drugsatfda_docs/label/2009 /021821s013s017s018lbl.pdf). ${ }^{2-6}$ Tigecycline binds to the $30 \mathrm{~S}$ ribosomal subunit blocking access of amino-acyl tRNA molecules to the A site, ${ }^{7}$ and is not affected by tetracycline resist- ance mechanisms: efflux pumps and ribosomal protection..$^{8-10}$ The expanded broad spectrum of activity of tigecycline includes a broad range of antibiotic-susceptible and -resistant gram-positive and gram-negative aerobes, anaerobes, and "atypical" bacteria. ${ }^{4}$

Hospital acquired pneumonia (HAP) is second only to urinary tract infections as the most common nosocomial infection contracted, especially among patients admitted to the ICU. ${ }^{11}$ In critical care settings and following surgical treatment, nosocomial pneumonia is reported in approximately $20 \%$ of patients and mortality rates range from 20-70\%. Methicillinresistant Staphylococcus aureus (MRSA) as well as gram-negative pathogens - Acinetobacter spp., Escherichia coli, Pseudomonas aeruginosa - are predominant pathogens in HAP; in addition, antibiotic resistance rates are elevated in these organisms complicating therapeutic decision-making. To evaluate the safety and efficacy of tigecycline in treatment of HAP infections a randomized, double-blind trial was conducted with imipenem/cilistatin as the active comparator. ${ }^{12}$ This analysis was conducted in order to evaluate the susceptibility of the clinical isolates to tigecycline and selected comparator agents.

\section{Materials and Methods}

\section{Clinical isolates}

Baseline pathogens from all patients enrolled in the clinical trial were included in the analysis of susceptibility data. Site laboratories processed patient specimens and cultured bacterial pathogens according to local practices. Acute HAP was defined as pneumonia with onset of symptoms $\geq 48$ hours after admission to an acute care hospital or chronic care facility (such as a skilled nursing home facility or rehabilitation unit), or $<7$ days after the subject was discharged from the hospital. The initial hospitalization must have been of $\geq 3$ days duration. Subjects must have had the presence of a new or evolving infiltrate on chest X-ray and the chest X-ray must have been obtained $\geq 48$ hours after the subject was admitted to the hospital or chronic care facility. Diagnosis required that the subjects have the presence of fever within 24 hours prior to randomization into the trial and leukocytosis or increased bands or leukopenia. In addition, subjects must have had at least two of the following: cough, dyspnea or tachypnea, pleuritic/inspiratory chest pain, auscultatory findings on pulmonary examination or rales and/or evidence of pulmonary consolidation, hypoxemia, purulent sputum or respiratory secretion or a change in sputum character occurring $\geq 48$ hours after hospitalization, or respiratory failure requiring mechanical ventilation (in lieu
Correspondence: C. Hal Jones, Wyeth Research, Bldg 200, Rm 3219, 401 N. Middletown Road, Pearl River, NY 10965, USA.

E-mail: jonesh3@wyeth.com

Key words: tigecycline, clinical isolates, in vitro susceptibility, MIC, hospital acquired pneumonia.

Contributions: all authors contributed significantly to the study. Study design was collaborative between $\mathrm{HJ}$ and PP, and all microbiology studies were conducted by PP. The molecular biology work was conducted by HJ and MT. The manuscript was written by $\mathrm{HJ}$ with editorial assistance from PP. All authors agree to the final draft of the manuscript as submitted.

Conflict of interest: $\mathrm{HJ}$ and PP were employees of Wyeth when the manuscript was drafted. $\mathrm{HJ}$ and PP are currently employees of Pfizer, and HJ holds stock in the company. MT has no conflicts of interest to declare.

Received for publication: 29 0ctober 2009. Revision received: 7 January 2010.

Accepted for publication: 11 January 2010.

This work is licensed under a Creative Commons Attribution 3.0 License (by-nc 3.0).

(C) Copyright P.J. Petersen et al., 2010

Licensee PAGEPress, Italy

Infectious Disease Reports 2010; 2:e1

doi:10.4081/idr.2010.e1

of having two of the clinical signs and symptom listed above). Respiratory tract specimens were obtained for Gram stain and culture at randomization. The majority of specimens submitted for culture were from: bronchoscopy, deep expectoration, or endotracheal aspiration; although it must be acknowledged that not all isolates described in the study were clinically relevant. Bacterial pathogens were sent to a central laboratory for identification and susceptibility testing. MICs were determined in Mueller-Hinton II broth (MHB); for streptococci MHB containing 5\% lysed horse blood was used. MICs were determined using custom-prepared dehydrated microdilution panels (Trek Diagnostics, Westlake, OH, USA) and followed reference methodology as described by the CLSI. ${ }^{13,14}$ Methicillin resistance of staphylococci was determined by MIC tests for oxacillin supplemented with $2 \% \mathrm{NaCl}$ and interpreted according to CLSI interpretive criteria. $^{13,14}$

\section{Confirmation of extended spectrum $\beta$-lactamase}

For those isolates of E. coli, Klebsiella pneumoniae or Proteus mirabilis resulting in a ceftazidime MIC of $\geq 2 \mu \mathrm{g} / \mathrm{mL}$, confirmation of the presence of an extended spectrum $\beta$-lactamase (ESBL) was performed using Etest ESBL 
strips containing either ceftazidime or cefotaxime with and without clavulanic acid, according to the manufacturer's instructions (ABBiodisk, Solna, Sweden).

\section{PCR analysis of resistance determi- nants}

Methicillin ( $S$. aureus) and tetracycline resistance determinants ( $S$. aureus, $E$. coli) were identified using diagnostic PCR assays as previously described. ${ }^{9,10}$ In addition, confirmed ESBL containing isolates were further examined by PCR to determine the class(es) of $\beta$ lactamase (e.g. TEM, SHV, CTX, OXA) encoded using protocols previously described..$^{15}$

\section{Results}

The most prevalent pathogens isolated from patients during the clinical trials (2004-2006) for HAP, including patients with ventilator associated pneumonia (VAP), are listed in Table 1. The distribution of pathogens was representative for the infection type and similar to reports from recent studies. ${ }^{16}$ A summary of the tigecycline susceptibility for the predominant baseline isolates obtained is presented in Table 2. The most prevalent pathogens isolated were Staphylococci spp. (287 isolates) with $S$. aureus represented by 75 methicillin-resistant (MRSA) and 130 methicillin-sensitive (MSSA) isolates (Tables 1, 2). Acinetobacter baumannii/calcoaceticus complex was the most prevalent gram-negative pathogen isolated ( 82 baseline isolates), followed by $E$. coli (75 isolates), $K$. pneumonia (75 isolates), and $P$. aeruginosa (54 isolates) (Table 1,2).

As shown in Table 2 and Supplementary Table, $92 \%$ of the MRSA isolates were susceptible to tigecycline ( $\mathrm{MIC}_{90} 0.5 \mu \mathrm{g} / \mathrm{mL}$ ). In the case of the MSSA isolates, $100 \%$ of the isolates were susceptible to tigecycline $\left(\mathrm{MIC}_{90} 0.25\right.$ $\mu \mathrm{g} / \mathrm{mL}$ ), and susceptibility rates for comparator agents were in excess of $91 \%$ with the exception of azithromycin (88\%) and ceftazidime (73\%) in the VAP population. Twentytwo MRSA and five MSSA isolates were resistant to minocycline (MIC $\geq 8 \mu \mathrm{g} / \mathrm{mL}$ ); of these, 24 isolates encoded tet(M), two isolates encoded tet(K) and tet(M), and a single isolate encoded tet(K) alone as determined by PCR analysis as previously described (Supplementary Table and data not shown). ${ }^{9}$ In addition, 10 isolates were minocycline susceptible (MIC $\leq 4 \mu \mathrm{g} / \mathrm{mL}$ ) and tetracycline resistant (MIC $\geq 8 \mu \mathrm{g} / \mathrm{mL}$ ); of these, four isolates encoded tet( $\mathrm{M})$, five isolates encoded tet(K), and a single isolate encoded both determinants. All of the methicillin susceptible isolates of Staphylococcus epidermidis were fully susceptible to $0.5 \mu \mathrm{g} / \mathrm{mL}$ of tigecycline $\left(\mathrm{MIC}_{90}\right.$

Table 1. Etiology of organisms cultured from patients with hospital acquired pneumonia.

\begin{tabular}{|c|c|c|c|c|}
\hline \multirow[t]{2}{*}{ Organism } & \multicolumn{2}{|c|}{ Non-VAP } & \multicolumn{2}{|c|}{ VAP } \\
\hline & N (\%) & $\begin{array}{l}\text { Multi-drug } \\
\text { resistant } \\
\text { isolates }(\%)^{\mathrm{a}}\end{array}$ & N (\%) & $\begin{array}{c}\text { Multi-drug } \\
\text { resistant } \\
\text { isolates }(\%)^{\mathrm{a}}\end{array}$ \\
\hline Gram-positive aerobes & $297(36 \%)$ & $101(34 \%)$ & $100(12 \%)$ & $42(42 \%)$ \\
\hline Staphylococcus aureus & $147(18 \%)$ & $50(34 \%)$ & $58(7 \%)$ & $25(43 \%)$ \\
\hline Staphylococcus epidermidis & $37(4.5 \%)$ & $28(76 \%)$ & $12(1.5 \%)$ & $10(83 \%)$ \\
\hline Enterococcus faecalis & $37(4.5 \%)$ & $7(19 \%)$ & $7(0.8 \%)$ & $3(43 \%)$ \\
\hline Streptococci pneumoniae & $22(2.7 \%)$ & & $5(0.6 \%)$ & \\
\hline Staphylococcus haemolyticus & $20(2.4 \%)$ & $16(80 \%)$ & $4(0.5 \%)$ & $4(100 \%)$ \\
\hline Enterococcus faecium & $4(0.5 \%)$ & & $2(0.25 \%)$ & \\
\hline Gram-negative aerobes & $268(33 \%)$ & & $154(18 \%)$ & \\
\hline $\begin{array}{l}\text { Acinetobacter baumannii / } \\
\text { calcoaceticus complex }\end{array}$ & $34(4.5 \%)$ & $27(79 \%)$ & $48(6 \%)$ & $25(52 \%)$ \\
\hline Escherichia coli & $58(7 \%)$ & $12(21 \%)$ & $17(2 \%)$ & $1(6 \%)$ \\
\hline Klebsiella pneumoniae & $61(7 \%)$ & $8(13 \%)$ & $14(1.7 \%)$ & \\
\hline Pseudomonas aeruginosa & $30(3.6 \%)$ & $4(13 \%)$ & $24(3 \%)$ & $7(29 \%)$ \\
\hline Enterobacter cloacae & $19(2.3 \%)$ & & $3(0.4 \%)$ & \\
\hline Haemophilus influenzae & $13(1.5 \%)$ & & $9(1.0 \%)$ & \\
\hline Klebsiella oxytoca & $11(1.3 \%)$ & & $2(0.2 \%)$ & \\
\hline Stenotrophomonas & $5(0.6 \%)$ & & $7(0.8 \%)$ & \\
\hline maltophilia & & & & \\
\hline Proteus mirabilis & $6(0.7 \%)$ & $2(33 \%)$ & $6(0.7 \%)$ & $2(33 \%)$ \\
\hline Enterobacter aerogenes & $4(0.5 \%)$ & $1(25 \%)$ & $7(0.8 \%)$ & $2(28 \%)$ \\
\hline Serratia marcescens & $6(0.7 \%)$ & $1(16 \%)$ & $4(0.5 \%)$ & $1(25 \%)$ \\
\hline
\end{tabular}

aMultidrug resistant strains are methicillin-resistant Staphylococcus aureus (MRSA) and S. Epidermidis (MRSE) isolates by default and pathogens having resistance to three classes of antibacterial agent. VAP, ventilator associated pneumonia.

$0.5 \mu \mathrm{g} / \mathrm{mL}$ ). Among the 38 isolates of MRSE there were three isolates with a tigecycline MIC of $1 \mu \mathrm{g} / \mathrm{mL}$ resulting in an overall susceptibility rate for these isolates of $92 \%\left(\mathrm{MIC}_{90} 0.5\right.$ $\mu \mathrm{g} / \mathrm{mL}$ ). When considering all 287 strains of Staphylococcus spp., the tigecycline $\mathrm{MIC}_{90}$ was $0.5 \mu \mathrm{g} / \mathrm{mL}$.

Tigecycline had good activity against all 50 isolates of Enterococcus spp. collected (Table 2 ). The predominant species obtained was Enterococcus faecalis (44 isolates) and all of the isolates were susceptible to $0.25 \mu \mathrm{g} / \mathrm{mL}$ (FDA susceptible breakpoint). By contrast, the $\mathrm{MIC}_{90} \mathrm{~s}$ for both levofloxacin (>16 $\mu \mathrm{g} / \mathrm{mL}$ ) and minocycline $(16 \mu \mathrm{g} / \mathrm{mL})$ were at the resistant breakpoints for the $E$. faecalis isolates (Supplementary Table).

Tigecycline activity was determined against 27 isolates of Streptococcus pneumoniae that included two isolates that were penicillin intermediate and two isolates that were penicillin resistant according to the recently changed penicillin breakpoints for this organism. ${ }^{13}$ All of the isolates were susceptible to $\leq 0.12 \mu \mathrm{g} / \mathrm{mL}$ tigecycline.

Tigecycline showed good activity against gram-negative organisms of which A. baumannii/calcoaceticus complex was the predominant pathogen isolated (Supplementary Table). The $\mathrm{MIC}_{90} \mathrm{~s}$ for all of the comparator agents were above the respective resistance breakpoints except for imipenem for the nonVAP isolates $\left(\mathrm{MIC}_{90} 2 \mu \mathrm{g} / \mathrm{mL}\right)$. CLSI or FDA breakpoints for tigecycline have not been established for this organism.

For the 75 baseline patient isolates of $E$. coli, $100 \%$ were susceptible to $2 \mu \mathrm{g} / \mathrm{mL}$ tigecycline (MIC range $0.12-2 \mu \mathrm{g} / \mathrm{mL}$ ) with an $\mathrm{MIC}_{90}$ of $0.5 \mu \mathrm{g} / \mathrm{mL}$ (Supplementary Table). Thirteen (17\%) of these isolates were multidrug resistant (MDR) strains showing resistance to ceftazidime, levofloxacin, and tetracycline with $\mathrm{MIC}_{90} \mathrm{~s}$ of $>64,16$, and $>64 \mu \mathrm{g} / \mathrm{mL}$, respectively. The $E$. coli collection included 48 tetracycline resistant (MIC $\geq 8 \mu \mathrm{g} / \mathrm{mL}$ ) strains, 26 of which were also resistant (MIC $\geq 8 \mu \mathrm{g} / \mathrm{mL}$ ) to minocycline. The tetracycline resistance determinants in these isolates were identified by PCR as previously described..$^{10}$ Twenty-five of the minocycline resistant isolates were found to encode tet(B), with two isolates also encoding tet(A) and a single isolate also encoding tet(C). One minocycline resistant isolate encoded only tet(A). Twenty-two isolates were found to be susceptible to minocycline (MIC $\leq 4$ $\mu \mathrm{g} / \mathrm{mL}$ ) and resistant to tetracycline (MIC $\geq 8$ $\mu \mathrm{g} / \mathrm{mL}$ ). All 22 isolates were found to encode tet(A), with four isolates also encoding tet(M) and two isolates also encoding tet(B). As previously shown, the presence of tetracyclineresistance determinants, specifically monospecific tetracycline efflux pumps, had no impact on tigecycline susceptibility of the isolates. ${ }^{10}$

Twenty-one $E$. coli isolates were identified as encoding ESBLs owing to a ceftazidime MIC $\geq 2 \mu \mathrm{gmL}$ and confirmed using E-test strips. As previously described, ${ }^{15}$ the class of $\beta$-lactamase responsible for the ESBL phenotype was deter- 
Table 2. In vitro activity of tigecycline against bacterial isolates cultured from patients with hospital acquired pneumonia.

\begin{tabular}{|c|c|c|c|c|c|c|c|c|c|c|c|c|c|}
\hline Organism (no. of strains) & \multicolumn{2}{|c|}{$\mathrm{MIC}_{50} \underset{(\mu \mathrm{g} / \mathrm{mL})}{\mathrm{MIC}_{90}}$} & $\% \mathrm{~S}^{\mathrm{a}}$ & \multicolumn{10}{|c|}{ No. of isolates with MIC $(\mu \mathrm{g} / \mathrm{mL})$ of } \\
\hline \multicolumn{14}{|l|}{ Gram-negative aerobes } \\
\hline Citrobacter freundii complex (5) & 0.5 & $N A^{b}$ & 100 & & & & 1 & 4 & & & & & \\
\hline Enterobacter aerogenes (11) & 1 & 2 & 91 & & & & 1 & 4 & 4 & 1 & & 1 & \\
\hline Enterobacter cloacae (22) & 0.5 & 1 & 100 & & & & 3 & 10 & 8 & 1 & & & \\
\hline Escherichia coli (75) & 0.25 & 0.5 & 100 & & & 13 & 36 & 23 & 2 & 1 & & & \\
\hline Klebsiella oxytoca $(13)$ & 0.25 & 2 & 100 & & & 1 & 5 & 4 & 1 & 2 & & & \\
\hline Klebsiella pneumoniae (75) & 0.5 & 2 & 96 & & & & 4 & 46 & 13 & 9 & 3 & & \\
\hline Proteus mirabilis (12) & 4 & 8 & 42 & & & & & & & 5 & 5 & 2 & \\
\hline Serratia marcescens (10) & 1 & 2 & 100 & & & & & & 8 & 2 & & & \\
\hline Haemophilus influenzae (22) & 0.25 & 0.5 & 100 & & 2 & 6 & 10 & 4 & & & & & \\
\hline $\begin{array}{l}\text { Acinetobacter calcoaceticus / } \\
\text { baumannii complex (82) }\end{array}$ & 1 & 4 & NA & & & 3 & 9 & 11 & 21 & 26 & 11 & 1 & \\
\hline Burkholderia cepacia (6) & 2 & NA & NA & & & & & & 1 & 3 & 2 & & \\
\hline Pseudomonas aeruginosa (54) & 16 & 32 & NA & & & & & & & & & 6 & 48 \\
\hline Stenotrophomonas maltophilia (12) & 1 & 2 & NA & & & & 1 & 3 & 5 & 3 & & & \\
\hline \multicolumn{14}{|l|}{ Gram-positive aerobes } \\
\hline Staphylococcus aureus (MRSA) (75) & 0.25 & 0.5 & 92 & & 1 & 25 & 33 & 10 & 4 & 2 & & & \\
\hline Staphylococcus aureus (MSSA) (130) & 0.12 & 0.25 & 100 & & 4 & 100 & 25 & 1 & & & & & \\
\hline Staphylococcus epidermidis (MRSE) (38) & 0.25 & 0.5 & 92 & & 2 & & 22 & 11 & 3 & & & & \\
\hline Staphylococcus epidermidis (MSSE) (11) & 0.12 & 0.5 & 100 & & 4 & 4 & & 2 & & & & & \\
\hline Staphylococcus haemolyticus (24) & 0.5 & 1 & 88 & & & 4 & 6 & 11 & 1 & 2 & & & \\
\hline Coagulase-negative Staphylococcus ${ }^{c}(9)$ & 0.25 & $\mathrm{NA}$ & 100 & & 1 & 2 & 4 & 2 & & & & & \\
\hline Enterococcus faecalis (VSE) (44) & 0.12 & 0.25 & 100 & & 9 & 29 & 6 & & & & & & \\
\hline Enterococcus faecium (VSE) (6) & 0.12 & NA & 100 & & 2 & 3 & 1 & & & & & & \\
\hline Streptococcus anginosus group ${ }^{\mathrm{d}}(5)$ & 0.06 & NA & 100 & & 2 & 3 & & & & & & & \\
\hline Streptococcus spp. viridans groupe (16) & 0.06 & 0.12 & 100 & 2 & 11 & 3 & & & & & & & \\
\hline Streptococcus pneumoniae $(27)$ & 0.06 & 0.12 & 100 & 8 & 14 & 5 & & & & & & & \\
\hline
\end{tabular}

a $\%$ S is the percent of strains susceptible at FDA susceptibility breakpoints for tigecycline: $\leq 2 \mathrm{~g} / \mathrm{mL}$ for Enterobactericeae, $\leq 0.5$ for Staphylococcus spp., $\leq 0.25$ for Streptococcus spp., $\leq 0.25 \mathrm{~g} / \mathrm{mL}$ for Enterococcus spp. and $\leq 4 \mathrm{~g} / \mathrm{mL}$ for anaerobes. ${ }^{\mathrm{b}} \mathrm{NA}$, not applicable owing to number of strains or no approved interpretive criteria are available. ${ }^{\mathrm{C}}$ S. capitis (2), S. hominis (4), S. saprophyticus (1), S. warneri (2). ${ }_{\mathrm{d}}^{\mathrm{S}}$. anginosus (2), S. constellatus (2), S. intermedius (1). E. mitis (2), S. oralis (8), S. parasanguis (1), S. salivarius (4), viridans Streptococcus (1). f. Pen-S (23), Pen-I (2), Pen-R (2). MSSA, methicillin-sensitive Staphylococcus aureus; MSSE, Methicillin-sensitive Staphylococcus Epidermidis; VSE, vancomycin-sensitive enterococci.

mined by PCR. Nineteen (90\%) of the isolates were found to encode a $b l a_{\mathrm{CTX}}$ family enzyme with various combinations of $b l a_{\mathrm{TEM}}, b l a_{\mathrm{SHV}}$, and $b l a_{0 X A}$ genes with fourteen isolates encoding the combination of $b l a_{\mathrm{CTX}}, b l a_{\mathrm{TEM}}$, and $b l a_{\text {OXA }}$ genes. One isolate was found to carry both a $b l a_{\mathrm{TEM}}$ and $b l a_{\mathrm{SHV}}$ gene, whereas another isolate encoded an AmpC $\beta$-lactamase of the $b l a_{\mathrm{CMY}}$ family. As previously described, E. coli encoding ESBLs are as susceptible as non-ESBL isolates to tigecycline. ${ }^{15}$

When tested against $K$. pneumoniae, tigecycline performed well with $96 \%$ of isolates susceptible and an $\mathrm{MIC}_{90}$ of $2 \mu \mathrm{g} / \mathrm{mL}$ for the 75 isolates tested (Table 2). Whereas in earlier studies $K$. pneumoniae had shown a tendency for elevated tigecycline MICs, only three isolates in the present study had an MIC of $4 \mu \mathrm{g} / \mathrm{mL}$. Eight (11\%) of the baseline isolates were MDR strains, resistant to a $\beta$-lactam and at least two other classes of agents, in this case levofloxacin and minocycline. The ESBL status of 31 isolates was confirmed (ceftazidime MIC $\geq 2$ $\mu \mathrm{g} / \mathrm{mL}$ and Etest positive) and the class of determinant responsible for the ESBL status identified by PCR. ${ }^{15}$ Twenty-four isolates encoded a $b l a_{\mathrm{SHV}}$ gene with 23 of the isolates encoding additional determinants in various combinations of the $b l a_{\mathrm{TEM}}, b l a_{\mathrm{CTX}}$, and $b l a_{\text {OXA }}$ classes. In the case of $b l a_{\mathrm{CTX}}, 19$ (79\%) isolates encoded this determinant with 16 isolates encoding both the $b l a_{\mathrm{SHV}}$ and $b l a_{\mathrm{CTX}}$ determinants. Two isolates encoded AmpC $\beta$-lactamases of the $b l a_{\mathrm{DHA}}$ family.

The 54 P. aeruginosa isolates collected during the clinical trial had $\mathrm{MIC}_{90} \mathrm{~s}$ in the resistant range for all of the comparator agents for which a breakpoint has been established. The tigecycline $\mathrm{MIC}_{90}$ was $32 \mu \mathrm{g} / \mathrm{mL}$, which is reflective of earlier studies demonstrating reduced susceptibility of this organism to tigecycline. ${ }^{17}$ P. aeruginosa expresses a family of multidrug efflux pumps (Mex pumps) that efficiently remove tigecycline from the cytoplasm, reducing its effectiveness. As would be expected, $P$. aeruginosa displayed low levels of susceptibility to ceftazidime (63-73\%; non-VAP, VAP), levofloxacin (57-63\%), and aminoglycosides (63-73\%) (Supplementary Table).

The activity of tigecycline was evaluated against 22 Enterobacter cloacae isolates with the result that all isolates were susceptible to 1 $\mu \mathrm{g} / \mathrm{mL}$. The findings were similar for the small collection (11) of Enterobacter aerogenes isolates: 10 of the 11 isolates were susceptible to $2 \mu \mathrm{g} / \mathrm{mL}$ tigecycline with one isolate having an MIC $=8 \mu \mathrm{g} / \mathrm{mL}$. Prior mechanistic studies revealed that a multidrug efflux system, AcrAB, is responsible for reduced tigecycline susceptibility in Enterobacter spp. ${ }^{18}$

Against the small collection of 12 P. mirabilis isolates, tigecycline showed results in agreement with what has been seen in prior studies: $\mathrm{MIC}_{90} 8 \mu \mathrm{g} / \mathrm{mL} .{ }^{19}$ All of the $P$. mirabilis isolates were resistant to minocycline (MIC range 16 $>64 \mu \mathrm{g} / \mathrm{mL}$ ). In addition, two baseline isolates were found to express the ESBL phenotype (ceftriaxone MIC $\geq 2 \mu \mathrm{g} / \mathrm{mL}$ and Etest positive), and PCR analysis revealed that one of the isolates encoded $b l a_{\mathrm{TEM}}, b l a_{\mathrm{CTX}}$, and $b l a_{\text {OXA }}$ family enzymes whereas the other isolate only encoded a $b l a_{\mathrm{TEM}}$ family enzyme.

\section{Discussion}

Tigecycline was specifically designed to overcome the two classical tetracycline resistance mechanisms, ribosomal protection proteins and monospecific tetracycline efflux pumps, while maintaining the broad spectrum of activity of the tetracycline class. ${ }^{1}$ During preclinical development, tigecycline was shown to have activity against a broad range of clinically important pathogens, including MRSA, VRE, and antibiotic resistant gram-neg- 
ative pathogens, as well as anaerobes and atypical bacteria. Tigecycline has demonstrated clinical utility and gained approval for use in treatment of cSSSI, cIAI, and CABP indications. ${ }^{2-6}$ The potent antibacterial activity of tigecycline demonstrated in our study echoed that seen in earlier clinical studies for the approved indications as well as during preclinical development. ${ }^{2-6}$ As expected, tigecycline activity in our study was not impacted by the presence of the classical tetracycline resistance mechanisms in $E$. coli and $S$. aureus or ESBL in E. coli, $K$. pneumonia, or $P$. mirabilis.

Clinical isolates were obtained from patients enrolled in 27 countries in North America, Latin America, Eastern Europe, Western Europe, Asia, South Africa, and Australia. There were no regional differences in the MICs of tigecycline noted for isolates from the various regions providing isolates. These results are in agreement with results obtained previously from a number of large in vitro susceptibility studies that included isolates from North America, Latin America, Europe, the Middle East, and Asia. ${ }^{20}$

Our study examined pathogens from both non-VAP and VAP patients and, for the most part, tigecycline activity was similar in both patient populations. The only exception to this finding for tigecycline was with $P$. aeruginosa. Owing to the fact that $9 \%$ (24 isolates) of VAP isolates were $P$. aeruginos $a$ and the tigecycline $\mathrm{MIC}_{90}$ for those isolates was $32 \mu \mathrm{g} / \mathrm{mL}$, this pushed the tigecycline $\mathrm{MIC}_{90}$ for the 255 VAP isolates to $8 \mu \mathrm{g} / \mathrm{mL}$. By comparison, for the non-VAP population, $P$. aeruginosa is only $5 \%$ (30 isolates) of isolates and, although the tigecycline $\mathrm{MIC}_{90}$ for these isolates is $32 \mu \mathrm{g} / \mathrm{mL}$, has less of an impact on the $\mathrm{MIC}_{90}$ for the 566 non-VAP isolates: $\mathrm{MIC}_{90} 2 \mu \mathrm{g} / \mathrm{mL}$. In the case of A. calcoaceticus/baumannii complex, the imipenem MIC $_{90}$ was $2 \mu \mathrm{g} / \mathrm{mL}$ for the non-VAP population and $32 \mu \mathrm{g} / \mathrm{mL}$ for the VAP population with $94 \%$ and $77 \%$ corresponding imipenem susceptibility. Tigecycline was the only agent tested with good activity $\left(\mathrm{MIC}_{90} 2\right.$ $\mu \mathrm{g} / \mathrm{mL}$ ) against the A.calcoaceticus/ baumannii complex isolates from VAP patients. Tigecycline has been shown to be safe and effective in double-blind, multicenter, global clinical trials for cSSSI, cIAI, and, most recently, CABP (see Tygacil label at http://www.accessdata.fda. gov/drugsatfda docs/label/2009/021821s013s017s018lbl.pdf). ${ }^{2,3,6}$ In summary, the in vitro activity of tigecycline against a broad spectrum of gram-positive and gram-negative pathogens isolated from patients enrolled in phase 3 clinical trials conducted worldwide for HAP showed an excellent susceptibility profile and suggests utility in the treatment of patients with this disease.

\section{References}

1. Jones C, Petersen P. Tigecycline: a review of preclinical and clinical studies of the firstin-class glycylcycline antibiotic. Drugs of Today 2005;41:637-59.

2. Ellis-Grosse E, Babinchak T, Dartois N, et al. The efficacy and safety of tigecycline in the treatment of skin and skin structure infections: results of two double-blind phase 3 comparison studies with vancomycin/aztreonam. Clin Infect Dis 2005;41:S341-53.

3. Babinchak T, Ellis-Grosse EJ, Dartois N, et al. The efficacy and safety of tigecycline in the treatment of complicated intra-abdominal infections: analysis of pooled clinical trial data. Clin Infect Dis 2005;41:S354-67.

4. Bradford PA, Weaver-Sands DT, Petersen PJ. In vitro activity of tigecycline against isolates from patients enrolled in phase 3 clinical trials for complicated skin and skin structure infections and complicated intraabdominal infections. Clin Infect Dis 2005; 41:S315-32.

5. Bradford PA, Petersen P, Tuckman M, et al. In vitro activity of tigecycline and occurrence of tetracycline resistance determinants in isolates from patients enrolled in phase 3 clinical trials for community acquired pneumonia. Clin Microbiol Infect 2008;14:882-6.

6. Dukart G, Dartois N, Cooper C, et al. Integrated results of 2 Phase 3 studies comparing tigecycline (TGC) with levofloxacin (LEV) in patients (Pts) with communityacquired pneumonia (CAP). 46th Interscience Conference on Antimicrobial Agents and Chemotherapy. San Francisco: American Society for Microbiology, 2006, Abstr L-1450.

7. Olson MW, Ruzin A, Feyfant E, et al. Functional, biophysical, and structural bases for antibacterial activity of tigecycline. Antimicrob Agents Chemother 2006;50:2156-66.

8. Jones CH, Murphy E, Bradford PA. Genetic determinants of tetracycline resistance and their effect on tetracycline and glycylcycline antibiotics. Anti-Infect Agents Med Chem 2008; 7:84-96.

9. Jones CH, Tuckman M, Howe AYM, et al. Diagnostic PCR analysis of the occurrence of methicillin and tetracycline resistance genes among Staphylococcus aureus isolates from phase 3 clinical trials of tigecycline for complicated skin and skin structure infections. Antimicrob Agents Chemother 2006;50:505-10.

10. Tuckman M, Petersen P, Howe AYM, et al. Occurence of tetracycline resistance genes among Escherichia coli isolates from the phase 3 clinical trials for tigecycline. Antimicrob Agents Chemother 2007;
51:3205-11.

11. Hidron AI, Edwards JR, Patel J, et al. NHSN annual update: antimicrobial-resistant pathogens associated with healthcareasso,ciated infections: annual summary of data reported to the National Healthcare Safety Network at the Centers for Disease Control and Prevention, 2006-2007. Infect Control Hosp Epidemiol 2008;29:996-1011.

12. Maroko R, Cooper A, Dukart G, et al. Results of phase 3 study comparing a tigecycline (TGC) regimen with an imipenem/cilastatin (IMI) regimen in treatment of patients (Pts) with hospital-acquired pneumonia (HAP). 47th Interscience Conference on Antimicrobial Agents and Chemotherapy. Chicago: American Society of Microbiology, 2007, Abstr L-730.

13. CLSI. Performance standards for antimicrobial susceptibility testing: M100-S19, 19th Informational Supplement. Wayne, PA: Clinical Laboratory Standards Institute, 2009.

14. CLSI. Methods for dilution antimicrobial susceptibility tests for bacteria that grow aerobically: Approved standard M07-A8, Eighth edition. Wayne, PA: Clinical Laboratory Standards Institute, 2009.

15. Jones CH, Tuckman M, Keeney D, et al. Characterization and sequence analysis of extended-spectrum-\{beta $\}$-lactamaseencoding genes from Escherichia coli, Klebsiella pneumoniae, and Proteus mirabilis isolates collected during tigecycline phase 3 clinical trials. Antimicrob Agents Chemother 2009;53:465-75.

16. Rea-Neto A, Niederman M, Lobo SM, et al. Efficacy and safety of doripenem versus piperacillin/tazobactam in nosocomial pneumonia: a randomized, open-label, multicenter study. Curr Med Res Opin 2008; 24:2113-26.

17. Dean CR, Visalli MA, Projan SJ, et al. Effluxmediated resistance to tigecycline (GAR936) in Pseudomonas aeruginosa PA01. Antimicrob Agents Chemother 2003;47:9728.

18. Keeney D, Ruzin A, Bradford PA. RamA, a transcriptional Regulator, and AcrAB, an RND-Type efflux Pump, are associated with decreased susceptibility to tigecycline in Enterobacter cloacae. Microb Drug Resist 2007;13:1-6.

19. Visalli MA, Murphy E, Projan SJ, et al. AcrAB multidrug efflux pump is associated with reduced levels of susceptibility to tigecycline (GAR-936) in Proteus mirabilis. Antimicrob Agents Chemother 2003;47:6659.

20. Sader HS, Jones RN, Stilwell MG, et al. Tigecycline activity tested against 26,474 bloodstream infection isolates: a collection from 6 continents. Diagn Microbiol Infect Dis 2005;52:181-6. 